\title{
Preparation of Microcrystalline Cellulose from Cotton and its Evaluation as Direct Compressible Excipient in the Formulation of Naproxen Tablets
}

\author{
Md. Nurul Islam Setu ${ }^{1}$, Md. Yeunus Mia ${ }^{2}$, Nur J aharat Lubna ${ }^{3}$ \\ and Abu Asad Chowdhury ${ }^{1}$
}

${ }^{1}$ Department of Pharmaceutical Chemistry, Faculty of Pharmacy, University of Dhaka, Dhaka 1000, Bangladesh

${ }^{2}$ Department of Pharmacy, State University of Bangladesh, Dhaka, Dhaka 1207, Bangladesh

${ }^{3}$ Department of Pharmacy, Primeasia University, Banani, Dhaka 1213, Bangladesh

Received: August 08, 2014; Accepted: October 18, 2014; Published (web): December 31, 2014

\begin{abstract}
Microcrystalline cellulose (MCC) was prepared by acid hydrolysis from the cellulose purified from the cotton. Chemical assay, determination of degree of polymerization (DP) and FT-IR confirm the identification of prepared microcrystalline cellulose. The FT-IR spectrum of synthesized MCC is very similar to that of Avicel® PH102, a commercial direct compression excipient, at consideration of both band position and intensity. The degree of polymerization (DP) of prepared MCC and Avicel PH102, determined from the value of intrinsic viscosity, were 210 and 240, respectively. The tableting properties of prepared MCC was excellent while formulating naproxen tablet. The hardness and friability of the tablets prepared from MCC was $5.33 \pm 0.45 \mathrm{~kg}$ and $0.077 \%$, respectively which were comparable to the tablets prepared from marketed Avicel PH102 having hardness and friability $7.35 \pm 0.41 \mathrm{~kg}$ and $0.063 \%$, respectively. The disintegration time of tablet prepared from MCC and Avicel PH102 was $8.25 \pm 0.41$ min and $4.50 \pm 0.28 \mathrm{~min}$, respectively. Again, the tablets prepared from MCC and Avicel PH102 showed more than $90 \%$ and $98 \%$ dissolution, respectively as per the USP specified medium. All these data indicate that the hardness, friability, disintegration and dissolution properties of tablets prepared by using our MCC comply with the USP specifications. This makes the prepared MCC as a promising candidate for direct compressible excipient of tablet.
\end{abstract}

Key words: Microcrystalline cellulose, cotton, direct compressible tablet, excipient

\section{INTRODUCTION}

Microcrystalline cellulose (MCC) is apartially depolymerised cellulose prepared by treating cellulose with mineral acids. It is one of the mostly used filler-binders in direct tablet compression. Its popularity in direct compression is due to its excellent binding properties when used as a dry binder. It also works as a disintegrant and lubricant and has a high dilution potential in direct compression formulations. In addition to its use in direct compression formulations, MCC is used as a diluent in tablets prepared by wet granulation as well

Correspondence to: Abu Asad Chowdhury Tel.: +8801711075120; Fax: +880-2-9667222;

E-mail: asaddg27@du.ac.bd

Dhaka Univ. J. Pharm. Sci. 13(2): 187-192, 2014 (December) as a filler for capsules and spheres. ${ }^{1}$ Traditionally, MCC has been prepared from bamboo, wood pulp, and viscose rayon..$^{2-4}$ Attempts have also been made to produce MCC from other sources such as newsprint waste, corncobs, bagasse, rice straw as well as fast-growing plants including Sesbania sesban, Pinus roxburghii and Crotalaria juncea. ${ }^{5-8}$ When cellulose reacts with acid, the $\beta(1-4)$ glycoside bond is attacked and the acetal linkage is broken resulting in the hydrolysis of the chain, thus decrease the degree of polymerization. ${ }^{9}$

In recent years, there has been enormous interest in producing MCC for pharmaceutical use because of its high compactness under minimum compression pressures, high binding capability, and ability to prepare tablets that are extremely hard, stable, yet disintegrate rapidly. ${ }^{10,11}$ All these properties make 
MCC particularly valuable as a filler and binder for tablet formulations prepared by direct compression. ${ }^{12,13}$

Naproxen is a nonsteroidal anti-inflammatory drug (NSAID), mainly used in pain and inflammation of rheumatic disease, advanced osteoarthritis and other musculoskeletal disorders, dysmenorrhoea and acute gout. ${ }^{14}$ It is widely used as an immediate release dosage form and in this study as a model drug to evaluate the prepared MCC as a direct compressible tablet excipient.

Report on extraction of microcrystalline cellulose from cotton rags has been published earlier. ${ }^{15,16}$ The preparation of microcrystalline cellulose depends upon the types of cellulose substrate due to the presence of different types of organic chemicals. In our case, the substrate contains large amount of seed particles which is totally different from other published data. In this article, we have extracted MCC from waste cottons in different methods. Moreover, we have evaluated the extracted MCC as a direct compressible excipient in formulation of naproxen tablets.

\section{MATERIALS AND METHODS}

Chemicals and reagents. Cotton was collected from local spinning mill. Copper (II) ethylenediamine solution was purchased from Fisher Scientific, USA. Commercially available microcrystalline cellulose, Avicel® PH 102, Fluka, supplied by Sigma Aldrich, USA, with an average size of $100 \mu \mathrm{m}$, was used as reference. All other reagents used were of reagent grade. Standard naproxen powder was collected as a gift from Beximco Pharmaceutical Ltd. Bangladesh.

Preparation of microcrystalline cellulose from cotton. Large size dirty materials from collected cotton were separated by hand. Then cotton (15 g) was then soaked in a solution containing $1 \%$ sodium hydroxide, $0.5 \%$ sodium dodecyl sulfate \& $0.1 \%$ of EDTA and heated at $100^{\circ} \mathrm{C}$ for 1 hour. The process was repeated with $8 \%$ sodium hydroxide solution at the same condition. After complete removal of the supernatant, the waste cotton was treated with $3.5 \%$ sodium hypochlorite solution for 1 hour at $60-70^{\circ} \mathrm{C}$.
Then the cotton was treated again with $17.5 \%$ sodium hydroxide at $100^{\circ} \mathrm{C}$ for 1 hour. The liquid was removed by filter to separate pure cellulose. The cellulose was washed with distilled water until neutralization. The cotton was then subjected to acid hydrolysis with $2.5 \mathrm{~N}$ hydrochloric acid for 1 hour at boiling condition. The acid solution was removed by filtration and the powder was washed with distilled water several times until neutral condition. The powder was dried at $60^{\circ} \mathrm{C}$ overnight and passed through 120 mesh sieve.

Chemical identification of microcrystalline cellulose. For chemical identification, the prepared powder $(10 \mathrm{mg})$ was dispersed in $2 \mathrm{ml}$ of iodinated zinc chloride solution composed on $1.9 \mathrm{~g} / \mathrm{ml}$ zinc chloride, $0.62 \mathrm{~g} / \mathrm{ml}$ potassium iodide, $0.05 \mathrm{~g} / \mathrm{ml}$ iodine.

Determination of degree of polymerization (DP). The degree of polymerization of cellulose samples is usually estimated from intrinsic viscosities of solutions of cellulose in copper (II) ethylenediamine solution (cuene). ${ }^{18}$ The copper (II) ethylenediamine solution was diluted by adding water (the ratio of the solution and water was 2:1) and different concentration of avicel PH102 (0\%, $0.125 \%, 0.25 \%, 0.5 \%, 1.0 \%$, and $2.0 \%$ ) were prepared by dissolving different amount of avicel PH102 in different volume of solvent. A blank was run at the same time. The time to move the avicel PH102 solution between the levels of viscometer was determined at $25^{\circ} \mathrm{C}$. The density of the avicel PH102 solution was also determined by a densitometer. The relative viscosity of avicel PH102 was determined by capillary viscometer. From the relative viscosity reduced viscosity was measured. The intrinsic viscosity was determined from the plot of reduced viscosity versus concentration. The intercept of y-axis of the plot is the intrinsic viscosity of the avicel PH102. From the value of intrinsic viscosity, the degree of polymerization was calculated using the following equation. ${ }^{18}$

(DP) $)^{0.85}=1.1 \times \eta$ (where $\eta$ is the intrinsic viscosity)

Fourier transform infra red (FTIR) spectroscopy. The microcrystalline cellulose sample 
was mixed with $\mathrm{KBr}(0.1 \% \mathrm{MCC})$ and grinded well to prepare fine powder and compressed to make disc. FTIR spectrum was recorded on FT-IR 8400S SHIMADZU spectrophotometer in frequency range of 4000-400 $\mathrm{cm}^{-1}$, with a resolution of $2 \mathrm{~cm}^{-1}$, in transmission mode. A total of 30 cumulative scans were taken.

Preparation of naproxen tablets using MCC. For the preparation of tablet, naproxen $(250 \mathrm{mg}), \mathrm{Na}-$ starch glycolate $(25 \mathrm{mg}), \mathrm{Mg}$-stearate $(5 \mathrm{mg})$ and microcrystalline cellulose $(320 \mathrm{mg})$ were weighed, mixed properly and subjected to direct compression using IR disk preparation apparatus.

Hardness of formulated naproxen tablets. The hardness of the prepared tablets was measured by using a hardness tester (Veego, India). The force required to break the tablet was measured in kilogram.

Friability test. Ten tablets were taken and weighed at a time. All the tablets were subjected to the chamber of Friabilator at $25 \mathrm{rpm}$ for $4 \mathrm{~min}^{17}$ After the specified time, the weight of all the tablets was measured and percent weight loss was calculated.

Disintegration of naproxen tablets. For disintegration test, six tablets were placed in the tube of USP disintegration test apparatus. The assembly was suspended in the beaker with $900 \mathrm{ml}$ distilled water as medium at $37 \pm 2^{\circ} \mathrm{C}$ at a rpm of 50 . The time required to disintegrate each tablet was measured. ${ }^{17}$

In vitro dissolution of the formulated naproxen tablets. In vitro dissolution of naproxen tablets was measured according to the USP30NF25. ${ }^{17}$ For this, six tablets were analyzed in USP dissolution type II apparatus at a speed of $50 \mathrm{rpm}$. The dissolution medium was $900 \mathrm{ml}$ of $0.1 \mathrm{M}$ phosphate buffer solution having $\mathrm{pH} 7.4$ at $37 \pm$ $0.5^{\circ} \mathrm{C}$. After $45 \mathrm{~min}, 5 \mathrm{ml}$ solution from each basket of the apparatus was collected, filtered, diluted if necessary and measured the absorbance at $332 \mathrm{~nm}$ using UV-VIS spectrophotometer (Model: UV 1700, Shimadzu). The amount of drug dissolved after 45 min was calculated from the standard curve of naproxen prepared by measuring the absorbance of naproxen solution having different concentration.

\section{RESULTS AND DISCUSSION}

Identification of prepared MCC. The microcrystalline cellulose prepared by treating the waste cotton with hydrochloric acid at $100^{\circ} \mathrm{C}$ was white, odorless and tasteless powder type material. The powder was subjected to iodinated zinc chloride solution. The sample showed violet-blue color in presence of the reagent. This indicates the powder as microcrystalline cellulose. ${ }^{17}$

Table 1. Degree of polymerization of prepared MCC and avicel PH102.

\begin{tabular}{|c|c|c|c|c|c|c|c|}
\hline Sample & Conc. $(\mathrm{g} / \mathrm{ml})$ & $\begin{array}{l}\text { Av. passing } \\
\text { time }(\mathrm{sec})\end{array}$ & $\begin{array}{c}\text { Density } \\
(\mathrm{g} / \mathrm{ml})\end{array}$ & $\begin{array}{l}\text { Relative } \\
\text { viscosity }\end{array}$ & $\begin{array}{l}\text { Reduced } \\
\text { viscosity }\end{array}$ & $\begin{array}{l}\text { Intrinsic } \\
\text { viscosity } \\
\text { (From graph) }\end{array}$ & $\begin{array}{l}\text { Degree of } \\
\text { polymerization } \\
\text { (DP) from equation }\end{array}$ \\
\hline \multirow{6}{*}{$\begin{array}{l}\text { Avicel } \\
\text { PH102 }\end{array}$} & 0 & 8.52 & 1.063 & 1.00 & & \multirow{6}{*}{40.65} & \multirow{6}{*}{240} \\
\hline & 0.00125 & 8.99 & 1.064 & 1.06 & 44.77 & & \\
\hline & 0.0025 & 9.65 & 1.064 & 1.13 & 53.14 & & \\
\hline & 0.005 & 11.21 & 1.064 & 1.32 & 63.34 & & \\
\hline & 0.01 & 15.32 & 1.065 & 1.80 & 80.05 & & \\
\hline & 0.02 & 30.05 & 1.066 & 3.53 & 126.71 & & \\
\hline \multirow{6}{*}{$\mathrm{MCC}$} & 0 & 8.52 & 1.064 & 1.00 & & \multirow{6}{*}{85.60} & \multirow{6}{*}{210} \\
\hline & 0.00125 & 9.48 & 1.058 & 1.11 & 90.14 & & \\
\hline & 0.0025 & 10.41 & 1.062 & 1.22 & 88.73 & & \\
\hline & 0.005 & 12.57 & 1.060 & 1.48 & 95.07 & & \\
\hline & 0.01 & 16.93 & 1.064 & 1.99 & 98.71 & & \\
\hline & 0.02 & 29.21 & 1.064 & 3.43 & 121.42 & & \\
\hline
\end{tabular}


We have measured the reduced viscosity of the prepared MCC and standard avicel PH102 by viscometer (Table 1). The intrinsic viscosity measured from y-intercept of the graph of reduced viscosity vs. concentration and was found to be 40.65 and 85.60 for avicel PH102 and prepared MCC respectively. The $\mathrm{R}^{2}$ value for the straight line of avicel PH102 and prepared MCC was 0.9958 and 0.9623 , respectively indicating a good correlation between the concentration and reduced viscosity (Figure 1). The calculated degree of polymerization of avicel PH102 and prepared MCC was 240 and 210, respectively. According to USP 2007, the DP of MCC should be less than 350 . This confirms again that the prepared sample is MCC.

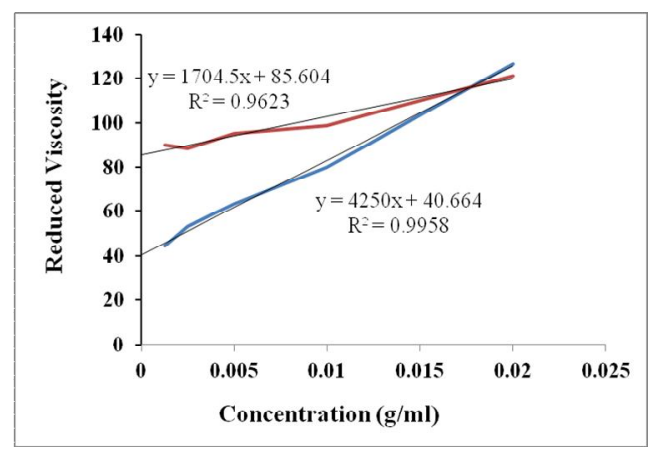

Figure 1. Determination of intrinsic viscosity of the microcrystalline cellulose.

To support the result, we further subjected the prepared sample and Avicel PH102 to FT-IR analysis. As shown in Figure 2, the peak intensity and positions are similar between the sample and reference sample, Avicel PH102 confirming further the MCC nature of the prepared sample.

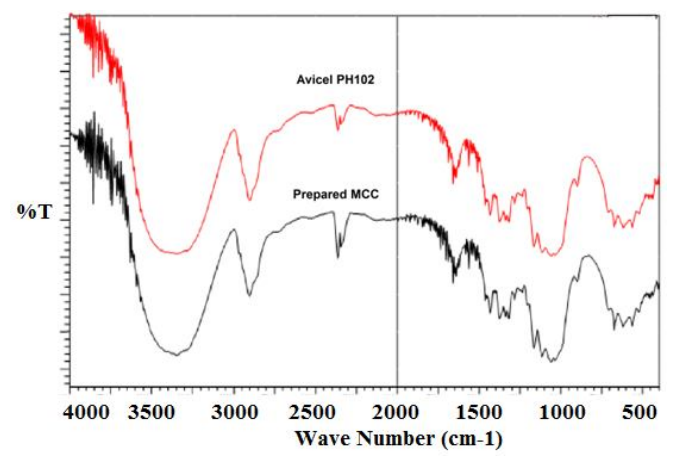

Figure 2. FTIR spectra of avicel PH102 and prepared MCC.
The FT-IR spectrum of avicel 102 and prepared MCC exhibited $\mathrm{O}-\mathrm{H}$ stretching absorption around $3449 \mathrm{~cm}^{-1}$, C-H stretching absorption around 2900 3000 $\mathrm{cm}^{-1}$, and C-O-C stretching absorptions around 1061 and $1104 \mathrm{~cm}^{-1}$. These absorptions are consistent with those of the typical cellulose backbone. ${ }^{19}$ The disappearance of the absorption peak at $1740 \mathrm{~cm}^{-1}$ in the spectrum indicates the absence of hemicellulose in the prepared microcrystalline cellulose. ${ }^{20}$ Moreover, the peak at $1595 \mathrm{~cm}^{-1}$ is associated with an aromatic ring stretch that is strongly associated with the aromatic $\mathrm{C}-\mathrm{O}$ stretching mode. ${ }^{21}$ This peak is an indicative of the presence of lignin in the sample. Absence of the peak at this position clearly indicates the high purity of prepared MCC. The $\mathrm{OH}$-stretching vibration broad band in the $3600-3100 \mathrm{~cm}^{-1}$ region gives considerable information regarding the hydrogen bonds. The peak characteristic of hydrogen bonds from the spectra of MCC became broader and with higher intensity. ${ }^{22}$ Broadband at this region with high intensity indicates higher crystallinity. Moreover, in the case of amorphous samples, the peak shifted to higher wave number values. The synthesized MCC shows same extent of shifting of the peak toward higher wave number and same level of broadband at this region as avicel 102 indicating comparable crystalline characteristic of the prepared MCC with avicel PH102.

Tableting properties of MCC. To evaluate the prepared MCC as direct compressible excipient, we have prepared naproxen tablet (Table 2) and assessed its possibility as a candidate for direct compressible tablet materials. After formulation of naproxen (250 mg) tablet using prepared MCC as direct compressible material, different physical parameters of the tablets such as hardness, friability, disintegration and dissolution were checked (table 3). The hardness and friability test was performed to confirm whether the prepared tablets can withstand the physical force during transportation. The hardness of tablet prepared using Avicel PH102 and MCC were 7.35 and $5.33 \mathrm{Kg}$, respectively. According to USP specification, oral tablets should have a 
hardness of 4 to $10 \mathrm{Kg}$. This indicates that the formulation of comply the USP specification for hardness test. The tablets from Avicel PH102 and MCC showed $0.063 \%$ and $0.077 \%$ weight loss after 100 revolutions ( $25 \mathrm{rpm}$ for $4 \mathrm{~min}$ ) in the friabilator. This also complies the USP specification for friability test (weight loss should not be more than $0.8 \%$ ).

Table 2. Formulation of naproxen tablets prepared by direct compression.

\begin{tabular}{lll}
\hline Components & Amount & Justification \\
\hline Naproxen & $250 \mathrm{mg}$ & Active ingredient \\
Na-starch glycolate & $25 \mathrm{mg}$ & Disintegrant \\
Mg-stearate & $5 \mathrm{mg}$ & Lubricant, Glidant \\
Microcrystalline & $320 \mathrm{mg}$ & $\begin{array}{l}\text { Direct compressible } \\
\text { materials }\end{array}$ \\
\hline
\end{tabular}

Tablet 3. Tableting properties of MCC.

\begin{tabular}{lll}
\hline Properties & avicel PH102 & MCC \\
\hline Hardness (Kg) & $7.35 \pm 0.41$ & $5.33 \pm 0.45$ \\
Friability (\%) & 0.063 & 0.077 \\
Disintegration time (min) & $4.50 \pm 0.28$ & $8.25 \pm 0.41$ \\
\% Drug dissolve in 45 min & $98.31 \pm 5.3$ & $90.23 \pm 6.2$ \\
\hline
\end{tabular}

The in vitro disintegration was performed for the tablets using USP apparatus. Both the formulated tablets disintegrate within 10 min indicating a good disintegration property of the tablets. The result follows USP specification for disintegration test. ${ }^{17}$ The formulated tablets were subjected to in vitro dissolution study using USP dissolution apparatus. All the formulations show more than $90 \%$ drug release in $900 \mathrm{ml}$ of $0.1 \mathrm{M}$ phosphate buffer (pH 7.4) at $50 \mathrm{rpm}$ within $45 \mathrm{~min}$. This confirms the USP specification for dissolution test (USP specification: $80 \%$ or more must be released within $45 \mathrm{~min}$ in specified condition).

Taken together, it can be concluded that the prepared MCC meets all the specifications of USP in respect to chemical identity and degree of polymerization. Not only that, the prepared MCC is a good candidate as a direct compressible excipient for formulation and manufacture of tablets.

\section{ACKNOWLEDGEMENTS}

The authors would like to thank the University Grants Commission (UGC) of Bangladesh for the financial support of this project. The authors are grateful to Beximco Pharmaceuticals Ltd., Bangladesh for providing gift sample of naproxen.

\section{REFERENCES}

1. Bolhuis, G.K. and Chowhan, Z.T. 1996. Materials for Direct compaction: Pharm. Powder Compact. Technol., Marcel Dekker, Inc., New York, pp. 419-500.

2. Sun, Y., Lin, L., Deng, H., Li, J., He, B., Sun, R. and Ouyang, P. 2008. Structural changes of bamboo cellulose in formic acid. Bioresources 3, 297-315.

3. Durand, H.W., Fleck, E.J. and Raynor, G.E. 1970. Microcrystalline cellulose compositions Co-dried with hydrocelluloses. US Patent 3537058, USA.

4. Battista, O.A. and Smith, P.A. 1962. Microcrystalline cellulose. Indst. Engin. Chem. 54, 20-29.

5. Bhimte, N.A. and Tayade, P.T. 2007. Evaluation of microcrystalline cellulose prepared from sisal fibers as a tablet excipient: a technical note. AAPS Pharm. Sci. Technol. 8, 1-6.

6. Nagavi, B.G, Mithal, B.M. and Chawla, J.S. 1989. Microcrystalline cellulose from corncobs. Res. Indust. 28, 277-280.

7. Jain, A.K., Dixit, V.K. and Varma, K.C. 1983. Preparation of microcrystalline cellulose from cereal straw and its evaluation as a tablet excipient. Indust. J. Pharm. Sci. 3, 8385.

8. El-Sakhawy, M. and Hassan, M.L. 2007. Physical and mechanical properties of microcrystalline cellulose prepared from agricultural residues. Carbohyd. Polym. 67, 1-10.

9. Hakansson, H. and Ahlgren, P. 2005. Acid hydrolysis of some industrial pulps: Effect of hydrolysis. Cellulose. 12, 177-183.

10. Dittgen, M. and Fricke, S. 1993. Microcrystalline cellulose in direct tableting. Mfg. Chem. 64, 17-21.

11. Doelker, E., Mordier, D., Iten, H. and Humbert-Droz, P. 1987. Comparative tableting properties of sixteen microcrystalline cellulose. Drug. Dev. Ind. Pharm. 13, 18471875.

12. Lamberson, E.M. and Raynor, G.E. 1976. Tableting properties of microcrystalline cellulose. Mfg. Chem. Aerosol. News. 47, 55-61.

13. Singla, A.K., Sakuja, A. and Malik, A. 1988. Evaluation of micrystalline cellulose prepared from absorbent cotton as direct compression carrier. Drug. Dev. Ind. Pharm. 14, 11311136.

14. Bangladesh National Formulary (BDNF) 2006. Directorate of Drug Administration, p. 303.

15. Baruah, P.P., Bhattacharya, G.C. and Chaliha, B.P. 2000. Microcrystalline cellulose from cotton. Indian Pulp. Paper. 5, 971-976 
16. Yuvraj, P.C., Sapkal, R.S., Sakpal, V.S. and Zamre, G.S. 2009. Microcrystalline cellulose from waste cotton rags (waste from garments and hosiery industries). Hydrogels for medical applications fabricated by oxidative-hydrolytic modification of cellulose. Int. J. Chem. Sci. 7, 681-688.

17. USP30-NF25. 2007. p. 2712.

18. Sihtola, H., Kyrkxund, B., Laamansn, L. and Palbmius, I. 1963. Comparison and conversion of viscosity and DP values determined by different methods. Pan. Рии. 45, 225-232.

19. Chen, L.M., Wilson, R.H. and McCann, M.C. 1997. Investigation of macromolecule orientation in dry and hydrated walls of single onion epidermal cells by FTIR microspectroscopy. J. Mol. Struct. 408, 257-260.
20. Revol, J.F., Stewart, D., Wilson, H.M., Hendra, P.J. and Morrison, I.M. 1982. On the cross-sectional shape of cellulose crystallites in Valonia ventricosa. Carbohyd. Polym. 2, 123-134.

21. Diana, C., Florin, C. and Valentin, I.P. 2011. Amrorphous Cellulose- Structure and Characterization. Cellulose Chem. Technol. 45, 13-21.

22. Kacurakova, M., Belton, P.S., Wilson, R.H. and Hirsch, J. 1998. Hydration properties of xylan-type structures: an FTIR study of xylooligosaccharides. J. Sci. Food. Agri. 77, 3844. 